\title{
As dinâmicas territoriais da agricultura familiar no município de Tabapuã - SP
}

\author{
The territorial dynamics of family agriculture in the municipality of Tabupuã - SP
}

\author{
Guilherme Valagna Pelisson \\ Doutorando do Programa de Pós-Graduação em Geografia (PPGGeo) \\ Universidade Federal de Jataí, Jataí - GO, Brasil \\ gvpelisson@yahoo.com.br
}

\begin{abstract}
Resumo
Este trabalho tem como objetivo compreender as estratégias dos agricultores familiares em períodos de expansões das culturas do café, da laranja e da cana-de-açúcar no município de Tabapuã - SP, desde a sua emancipação político-administrativa como município em 1929 até o ano de 2015. Fezse necessário, coleta de dados secundários (IBGE, Fundação Seade, Casa da Agricultura, visita ao Sindicato dos Trabalhadores Rurais e Biblioteca Municipal); estabeleceu-se saltos temporários no século XX (períodos onde as expansões tiveram seu ápice, periodização) e trabalho de campo em estabelecimentos com predominância da agricultura familiar. Após a sistematização dos dados e alinhados as abordagens selecionadas, analisou a principal produção da unidade familiar e suas estratégias de manutenção no campo e chegou as seguintes situações: as quais salientam que os períodos analisados desencadearam estratégias diversas, processos de organização/reorganização socioespacial da unidade territorial, ocasionando a desarticulação e redução de agricultores familiares nas últimas décadas, mas não o fim da atividade, que vem se mantendo e se ressignificando. Nesse cenário verificou-se também que não há uma assistência efetiva de auxílio (assistência técnica) para esses agricultores no quesito de manutenção de suas atividades tradicionais e/ou com programas de financiamento. A valorização desses indivíduos e a manutenção de suas atividades com garantia para sua permanência no campo só é possível por meio de políticas públicas que os valorizem e que os reconheçam como fundamentais para o abastecimento da merenda escolar, das feiras, dos (super)mercados, e como fornecedores de alimentos para as mesas dos brasileiros.
\end{abstract}

Palavras-Chave: Dinâmica territorial; Café; Laranja; Cana-de-Açúcar; Tabapuã - SP.

\begin{abstract}
This work aims to understand the strategies of family farmers in periods of expansion of coffee, orange, and sugar cane crops in the municipality of Tabapuã - SP, since its political and administrative emancipation as a municipality in 1929 until 2015. It was necessary to collect secondary data (IBGE, Fundação Seade, Casa da Agricultura, visiting the Sindicato dos Trabalhadores Rurais and the local library); temporary leaps were established in the twentieth century (periods when the expansions had their peak, periodization) and fieldwork in establishments with the predominance of family agriculture. After systematizing the data and aligning the selected approaches, it was analyzed the primary production of the family unit and its strategy for maintaining the field, and it reached the following situations: which point out that the periods analyzed triggered different strategies, organization processes/ socio-spatial reorganization of the territorial unit, causing the disarticulation and reduction of the family farmers in the last decades, but not the end of the activity, which has been maintained and reframed. In this scenario, it was also verified that there is no effective assistance (technical assistance) for these farmers in terms of maintaining their traditional activities and/or with financing programs. The valorization of these individuals and the maintenance of their activities with the guarantee of their permanence in the field is only possible through public policies that value them and that recognize them as fundamental for the supply of school meals, fairs, (super) markets, and as food providers for Brazilians' tables.
\end{abstract}

Key-words: Territorial Dynamics; Coffee; Orange; Sugar Cane; Tabapuã - SP. 


\section{INTRODUÇÃO}

A agricultura familiar no município de Tabapuã - SP vem passando por ressignificações, tendo que se adaptar a cada apogeu de políticas públicas de expansão de um determinado cultivo, em sua maior parte os agricultores que conseguem algum tipo de financiamento ou que possuem capital para investimento tentam associar sua produção, adequando sua propriedade para uma monocultura, assim é a realidade do município desde sua emancipação política e administrativa.

Diante disso, este trabalho tem por finalidade compreender as estratégias dos agricultores familiares do município de Tabapuã - SP, nos períodos de expansão dos cultivos de café, da laranja e da cana-de-açúcar, de 1929 (data de sua emancipação política administrativa, como município) a 2015 (ano final da referida pesquisa), no município de Tabapuã - SP (Figura 1), buscando entender, assim, as dinâmicas territoriais.

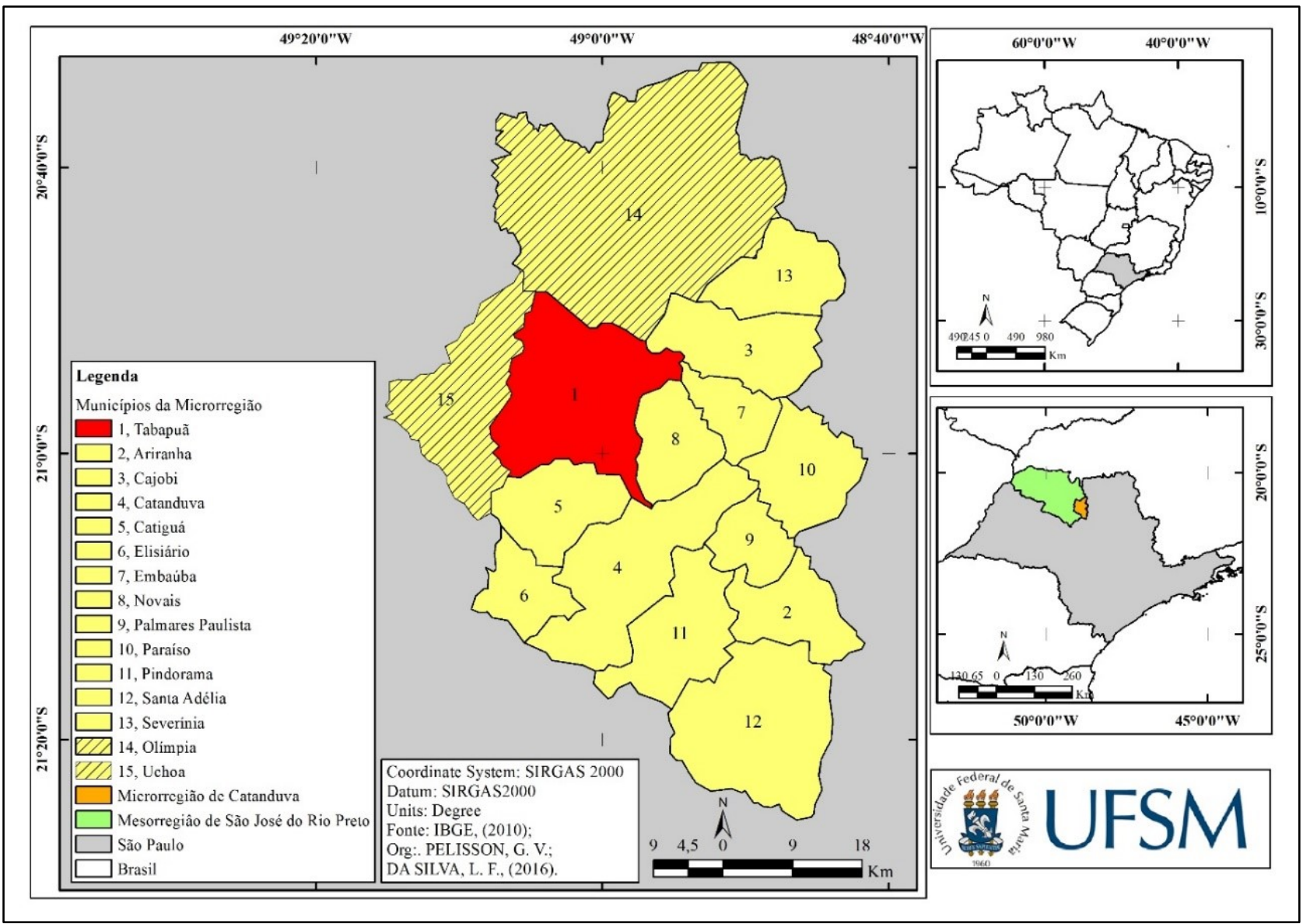

Figura 1 - Localização do município de Tabapuã, SP.

Fonte: IBGE (2010).

A escolha pelas culturas do café, da laranja e da cana-de-açúcar justifica-se para análise, uma vez que o território passa por transformações que permitiram um crescimento no setor econômico, político, espacial, ambiental e cultural desta unidade territorial e forçaram a agricultura familiar a se (re)organizar no espaço, por meio da relação homem - natureza. 
O objetivo deste estudo consiste em compreender as dinâmicas territoriais que os agricultores familiares utilizam como estratégias para a manutenção e a permanência no rural do município. A questão-problema apresentada se baseia na indagação de que os agricultores familiares se mantiveram no rural se relacionando fragilmente com a lógica capitalista, porém, com o avanço dos meios de produção da cana-de-açúcar este frágil equilíbrio estaria comprometido, uma vez que a prática de arrendamento pode estar diminuindo o quantitativo da presença da unidade familiar no rural e aumentando a concentração de terra e a produção da diversidade de alimentos.

$\mathrm{Na}$ intenção de um melhor caminho interpretativo sobre as ações ocasionadas no território da dualidade entre a agricultura familiar e a agricultura patronal, foram estabelecidos os procedimentos para a análise.

\section{ALINHAMENTOS TEÓRICOS E DE MÉTODO PARA O DESENVOLVIMENTO DA PESQUISA (PROCEDIMENTOS)}

Para o estudo proposto sobre agricultura familiar foram selecionados indivíduos (agricultores familiares) que se enquadrassem nos seguintes critérios: a) indivíduos que constituem uma base familiar para manter a propriedade rural; b) que se enquadram na Lei $\mathrm{n}^{\circ} 11.326$, de 24 de julho de 2006; e c) que possuem até quatro (4) módulos fiscais, o que em Tabapuã corresponde a 64 hectares.

Entende-se também que, de acordo com a lei, a mesma não só se refere à área, por isso, atentou-se também para a renda familiar e a condição da propriedade, sendo essa do proprietário, cedida por empregador ou até mesmo ocupada.

Neste trabalho realizou-se uma pesquisa quanti-qualitativa, em que os dados quantitativos coletados foram utilizados para apresentar um panorama geral do município, abordando temáticas de grande importância que adquirem visibilidade por meio de informações estatísticas. Os métodos quantitativos, de acordo com Richardson (2008) são utilizados no desenvolvimento da pesquisa e fornecem uma precisão dos resultados, ou a intenção, evitando distorções de análise e interpretação, contribuindo, portanto, para uma melhor margem de segurança quanto às deduções.

Nesse sentido, os dados quantitativos utilizados foram obtidos através dos Censos Demográficos e Agropecuários do IBGE, do projeto LUPA da Fundação Seade, do CANASAT, assim como de consultas a órgãos públicos e a outros estudos da região que apresentassem dados estatísticos de interesse para este trabalho.

Destaca-se que foram realizadas visitas à unidade de Catanduva e São José do Rio Preto, $\mathrm{SP}$, do IBGE, em que se realizou uma pesquisa documental de cunho quantitativo, e se buscou dados sobre a composição da população do município de Tabapuã nos Censos Demográficos que estavam disponíveis nestas unidades referentes aos anos de 1940, 1950, 1960, 1970, 1980, 1991, 
2000 e 2010. E dos cultivos de café, laranja e cana-de-açúcar, nos Censos Agropecuários de 1960, 1970, 1980, 1985, 1995 e 2006 e Produção Agrícola Municipal de 2013.

A obtenção desses dados foi necessária para que se pudesse fazer uma análise da população que ocupava a área que atualmente pertencente ao município de Tabapuã, já que durante a realização destes Censos na área desse município havia distritos que hoje estão emancipados (como é o caso de Novais e Ibarra, parte do atual município de Catiguá).

Ao fazer referência a esse tipo de levantamento de dados, Gil (1999) destaca que a diferença entre pesquisa documental e pesquisa bibliográfica é a natureza das fontes.

Enquanto a pesquisa bibliográfica se utiliza fundamentalmente das contribuições dos diversos autores sobre determinado assunto, a pesquisa documental vale-se de materiais que não receberam ainda um tratamento analítico, ou que ainda podem ser reelaborados de acordo com os objetivos da pesquisa (GIL, 1999, p. 66).

De acordo com Gil (1999), as fontes documentais podem referir-se a documentos de primeira mão que não receberam tratamento nenhum, tais como documentos oficiais, reportagens de jornal, cartas, contratos, diários, filmes, fotografias, gravações, etc., e a documentos de segunda mão, que, de alguma forma, já foram analisados, como relatórios de pesquisa, relatórios de empresas, tabelas estatísticas.

Também se buscou informações em primeira mão na Prefeitura Municipal de Tabapuã e no Sindicato dos Trabalhadores Rurais no intuito de complementar as já existentes. Contudo, as informações quantitativas serviram para explicar uma determinada realidade, mas a compreensão da mesma fundamentou-se nas informações qualitativas.

Diante disso, a utilização das duas abordagens, cada uma com seu uso apropriado, foi capaz de gerar resultados, visto que a abordagem quantitativa possui força na validade externa, já que seus dados podem ser generalizáveis para um conjunto, porém, demonstram fragilidade na validade interna, já que podem não representar a realidade de determinado local (LINDNER, 2011, p. 24).

De outra forma, "a abordagem qualitativa possui força na validade interna ao enfocar as particularidades e especificidades locais e fragilidade na validade externa, pois tem pequena probabilidade de generalização" (LINDNER, 2011, p.24). Assim, para Neves (1996), o uso dos dois métodos se complementa, ou seja, mesmo se diferindo na forma e na ênfase, os métodos quantitativos e qualitativos não se excluem, sendo que o método qualitativo traz uma contribuição intuitiva para um trabalho racional.

O ponto forte da abordagem qualitativa encontra-se nas particularidades e especificidades dos fenômenos (LINDNER, 2011, p. 24). Segundo Richardson (2008), a abordagem do método 
qualitativo justifica-se por ser uma forma de fenômeno social que tem como objetivos situações complexas ou estritamente particulares.

Os estudos que empregam uma metodologia qualitativa podem descrever a complexidade de determinado problema, analisar a interação de certas variáveis, compreender e classificar processos dinâmicos vividos por grupos sociais, contribuir com o processo de mudança de determinado grupo e possibilitar, em maior nível de profundidade, o entendimento das particularidades do comportamento dos indivíduos (RICHARDSON, 2008, p. 80).

Para Creswell (2007), a pesquisa qualitativa se baseia em texto e imagem, passando por diversos métodos, como observações diretas, entrevistas. Em um primeiro momento, como forma de coletar as informações qualitativas, buscou-se as bases históricas do local estudado. A pesquisa histórica, na concepção de Richardson (2008), preocupa-se com o registro escrito dos acontecimentos.

Dessa forma, utilizou-se fontes primárias e secundárias na pesquisa sobre a história do município de Tabapuã e do Noroeste Paulista. As fontes primárias referem-se a relatos de moradores do município e da região, além de fotografias antigas e visitas aos Museus e órgãos do município que contribuíram para o entendimento das informações obtidas através das fontes secundárias, em livros e trabalhos acadêmicos sobre a temática.

A observação representou outra etapa de fundamental importância nesta pesquisa. Em relação à mesma, Gil (1999) coloca que essa técnica realiza um papel fundamental na pesquisa, presente em todo o trabalho e em variadas etapas desde a criação do problema até a análise dos dados, mas é na coleta de dados que acaba sendo mais utilizada, aliada a outras técnicas ou com um formato mais exclusivo. Dessa forma, a observação nessa pesquisa esteve presente nas etapas de pesquisa de campo em que se observou a paisagem estática e móvel do município de Tabapuã.

Para Richardson (2008, p. 259), “[...] observação é o exame minucioso ou a mirada atenta sobre um fenômeno no seu todo ou em algumas partes; é a captação precisa do objeto examinado". Diante disso, a partir de um diário de campo foram feitas as considerações e, além das anotações, concomitantemente às outras técnicas de pesquisa citadas, foram realizadas entrevistas com informantes qualificados.

Para a seleção dos entrevistados e dos critérios para serem analisados, buscou-se trabalhos de autores que possuem publicações acadêmicas voltadas para a agricultura familiar. E concluiu que os informantes selecionados (os sujeitos) seriam de participação ativa, escolhidos de forma aleatória, que fossem agricultores familiares, que as propriedades se enquadrassem na Lei $n^{\circ} 11$. 326 de 24 de julho de 2006, a mão de obra fosse familiar e que a propriedade fosse própria, cedida, alugada ou ocupada. Também foram selecionados sujeitos influentes nas tomadas de decisões 
políticas e sociais no município, além de pessoas externas ao local que tivessem informações de grande valor para a temática estudada.

A escolha pela entrevista deu-se por esta representar uma técnica que possibilita obter do entrevistado suas descrições pessoais, observar como ele identifica os problemas e estabelecer o contato com o sujeito da pesquisa. Todas as entrevistas realizadas neste estudo foram guiadas. Nesse tipo de entrevista, segundo Richardson (2008), o pesquisador conhece previamente os aspectos que deseja pesquisar e com base neles formula alguns pontos para tratar com o entrevistado.

As perguntas dependem do entrevistador e o entrevistado tem a liberdade de se expressar como quiser, guiado pelo entrevistador. A liberdade de expressão do entrevistado nesse caso possui uma importância fundamental, pois a intenção das entrevistas nesse estudo foi entender o que os entrevistados pensavam sobre determinados assuntos, ou seja, suas percepções (LINDNER, 2001, p. $82)$.

Portanto, foram realizadas diversas visitas ao município de Tabapuã nos meses de julho e dezembro de 2014 e janeiro, fevereiro, março, abril, junho e julho de 2015, objetivando coletar informações por meio de entrevistas, observações, conversas informais com membros da comunidade e representantes dos poderes públicos, além de pesquisas documentais na Biblioteca Municipal e Museus.

Foram entrevistadas 20 famílias de agricultores, haja vista que do número de 30 propriedades propostas, apenas 20 propriedades foram encontradas com moradores, as demais tinham se anexado a propriedades maiores ou não morava mais ninguém nelas.

Com a pesquisa de campo pretendeu-se entender a lógica predominante que se estabeleceu e se estabelece no meio rural tabapuanense. O contato com a realidade por meio da observação, do diálogo e do registro fotográfico proporciona uma dialética com outros registros de outros pesquisadores ocasionando o debate que fundamenta a pesquisa. No método dialético, o campo como realidade não é externo ao sujeito, o campo é uma extensão do sujeito, como é numa outra escala a ferramenta para trabalhar uma extensão do seu corpo, ou seja, a pesquisa é fruto da interação dialética entre sujeito e objeto (SUERTEGARAY, 2009, p. 2).

Uma base para uma lógica da dialética materialista é trabalhar com variáveis que, tencionadas entre si, a partir de uma contradição, movam-se para uma terceira situação. Portanto, uma variável para trabalhar com uma lógica da dialética são as transformações que vão ocorrendo no decorrer do tempo (desenvolvimento da técnica), proporcionando novos olhares e modos de produzir impulsionados pelas exigências de mercado e pelas políticas públicas. 
Com os dados obtidos, pode-se mensurá-los e equipará-los com o corpo bibliográfico levantado, com as informações obtidas em órgãos municipais, como a Secretaria da Cultura, a Biblioteca Municipal e a Casa da Agricultura (documentos, mapas).

Além de investigar grandes produtores (agricultura patronal) rurais detentores da maior parte de área plantada e colhida em hectares no município, para assim poder entender os efeitos ocasionados pelos mesmos, esta investigação atentou para os agricultores familiares, que é o foco desse estudo.

Dessa forma, as diversas informações obtidas na pesquisa de campo possibilitaram a caracterização da dinâmica espacial e social do município de Tabapuã.

Passa-se, então, a entender as relações de apropriação do território que vem ocorrendo em Tabapuã na produção agrícola.

\section{O USO DO TERRITÓRIO NO ENTENDIMENTO DA FRÁGIL RELAÇÃO ENTRE OS AGRICULTURES FAMILIARES E A LÓGICA CAPITALISTA DA AGRICULTURA PATRONAL, RESULTANDO EM SUAS DINÂMICAS}

Para entender as dominações da agricultura patronal e as articulações da agricultura familiar, buscou-se explicações por meio da abordagem territorial, a qual, segundo Bernadelli (2004), permite compreender, nas pesquisas, a dinâmica dos conflitos de luta na terra contra a supremacia da agricultura patronal, corroborando com o domínio exercido pelas grandes empresas do setor agroindustrial canavieiro, que visam novos mercados para produzirem e reproduzirem seu capital.

De acordo com Saquet (2007, p. 183), “[...] a abordagem territorial consubstancia-se numa das formas para se compreender a miríade de processos, redes, rearranjos, a heterogeneidade, contradições, os tempos e os territórios de maneira a contemplar a (i)materialidade do mundo da vida".

Para Santos (2011, p. 322), a utilização da abordagem territorial na compreensão do espaço agrário do território e da agricultura familiar faz sentido na medida em que contribui para uma visão mais integrada do espaço, percebendo suas multifacetas, ao mesmo tempo em que tem na sua identidade territorial um elo que permita sua dinamização.

No Brasil, segundo Schneider (2009, p. 28), "o debate sobre agricultura familiar ainda é recente e não possui contornos definido". E destaca alguns estudos publicados em português, como o de Veiga (1991), Abramovay (1992), e Lamarche (1993,1999), que deram impulso decisivo a esta temática.

O autor ainda complementa colocando que, ao se retomar a bibliografia brasileira (recente) sobre os processos sociais rurais e agrários, pode-se perceber que a incorporação da expressão 
agricultura familiar ganhou projeção somente a partir do final dos anos oitenta, sobretudo, a partir da primeira metade da década de 1990.

Na década de 1990, no Brasil, foi inserido um conceito (agricultura familiar) ligado a campos temáticos e bibliográficos constituídos a partir dos modos de organização dos agricultores estadunidenses - Family farm - esses se diferenciavam por critérios de utilização da força de trabalho e modo de gestão da produção social. No Brasil, esse termo foi absorvido e traduzido como “Agricultura Familiar", e promulgado através de políticas públicas para com esses sujeitos, como coloca Neves (2008, s.p.).

Têm-se então que é difícil pensar a agricultura familiar como homogênea devido à diversidade (características sociais, econômicas, físicas). Porém, deve-se analisar as especificidades e o fio condutor que há em comum.

Para compreender o espaço de reprodução da agricultura familiar no Brasil não basta, entretanto, desenhar os seus contornos, calculando sua dotação em recursos produtivos (WANDERLEY, 1995, p. 40). É preciso, igualmente, entender que esse é um espaço em construção, na maioria das vezes, precário e instável, cuja viabilidade depende frequentemente da tenacidade dos agricultores e da adoção de complexas estratégias familiares (WANDERLEY, 1995, p. 40), sendo uma delas as atividades não agrícolas, que, segundo Carneiro (2008), não são recentes, mas se ressignificam.

Em resumo, no Brasil, o termo agricultura familiar, para Neves (2008, s.p.), corresponde então à convergência de esforços de certos intelectuais, políticos e sindicalistas articulados pelos dirigentes da Confederação Nacional dos Trabalhadores na Agricultura, mediante apoio de instituições internacionais, mais especialmente a Organização das Nações Unidas para a Agricultura e Alimentação (FAO) e o Banco Internacional de Reconstrução e Desenvolvimento (BIRD).

Na perspectiva de Guanziroli sobre a agricultura familiar na região Sudeste, que é a região em que este estudo ocorreu, o autor enxerga que há um peso reduzido nessa região: “Ainda assim, em termos absolutos sua contribuição não pode ser menosprezada, inclusive porque registra níveis elevados de capitalização e dinamismo" (GUANZIROLI, 2001, p. 157).

Guanziroli (2001) afirma que na região Sudeste as histórias apresentam tantas particularidades locais que seria inútil delas se abstrair em busca de um padrão comum, ao contrário das demais regiões, onde a dinâmica da agricultura familiar é diversificada, mas segue um padrão que pode ser generalizado (ocupação de fronteira, migração europeia, etc.).

Em todo caso, é possível apontar que também no Sudeste a dinâmica da agricultura familiar está intimamente ligada ao movimento da agricultura patronal, seja a cultura do café, algodão, cana-de-açúcar ou fazendas de gado em Minas. Ao contrário do que ocorreu no Sul, onde a agricultura familiar constitui um segmento próprio, autônomo, na maioria dos estados da região Sudeste os produtores familiares estão nos interstícios da grande 
propriedade, sujeitos aos movimentos de expansão e crise que vem afetando as principais atividades exploradas pela agricultura patronal (GUANZIROLI, 2001, p. 157).

Entende-se então que ao se analisar a categoria analítica e a construção da categoria normativa da agricultura familiar e do agricultor familiar percebe-se e entende-se que não é recente a preocupação com esses indivíduos menos favorecidos e excluídos de um processo capitalista, que a busca pela compreensão é constante e que existem períodos em que autores renovam suas interpretações e criam novas perspectivas positivas e negativas, identificando acertos e erros governamentais por meio de políticas públicas. E que os sindicatos e movimentos sociais do campo passaram a se identificar com a noção de agricultura familiar que, na verdade, congregava uma miríade de categorias sociais unificadas sob uma mesma denominação (SCHNEIDER, 2009, p. 36). A afirmação da agricultura familiar no cenário social e político brasileiro está relacionada à legitimação que o Estado lhe emprestou ao criar o Programa Nacional de Fortalecimento da Agricultura Familiar (PRONAF), em 1996. (SCHNEIDER, 2009, p. 36)

Como forma de alternativa de articulação com uma lógica capitalista de agricultura que vinha se desenvolvendo, Candiotto (2011) acredita que apesar de haver a existência dessa polaridade no cenário rural entre agricultura não-familiar (agricultura patronal, agricultura industrial, agronegócio) e agricultura familiar, ele não vê as duas realidades como contrapostas, para o mesmo, é possível a incorporação de técnicas e métodos de cultivo e manejo agropecuário provenientes do agronegócio por parte de diversas unidades produtivas familiares, como por exemplo: "a integração dos agricultores familiares com grandes agroindústrias, para a criação de aves, suínos, leite, fumo, entre outros produtos".

Fica evidente, em contato com os agricultores familiares do estudo, que o pacote do agronegócio, desenvolvido pela agricultura patronal, vem influenciando as atividades e o modo de vida familiar e que há uma tendência de ampliação desta influência já descrita por Candiotto (2011, p. 277).

Sobretudo, quando analisados os dados estatísticos dos estabelecimentos agropecuários tabapuanenses, de acordo com o IBGE (Censo Agropecuário de 2006), há 276 unidades de estabelecimentos agropecuários de agricultura familiar em 4.132 hectares e 124 unidades de estabelecimentos agropecuários não-familiares que ocupam uma área de 23.531 hectares, ou seja, há concentração de terras onde se tem muitos hectares em mãos de poucos, e, ao mesmo tempo, têm-se muitos agricultores familiares com poucas terras. Nesse sentido, fica perceptível, a partir da metodologia utilizada pelo IBGE, a forte presença da lógica capitalista agropecuária, estimulada pelo agronegócio no município, e uma economia rural voltada para a produção de commodities.

Quando analisado a Figura 1, evidencia-se a área plantada em hectares dos cultivos de café, laranja e cana-de-açúcar de 1960 a 2013. A seguir, tem-se a explanação dessa realidade. 


\section{Área plantada (em hectares)}

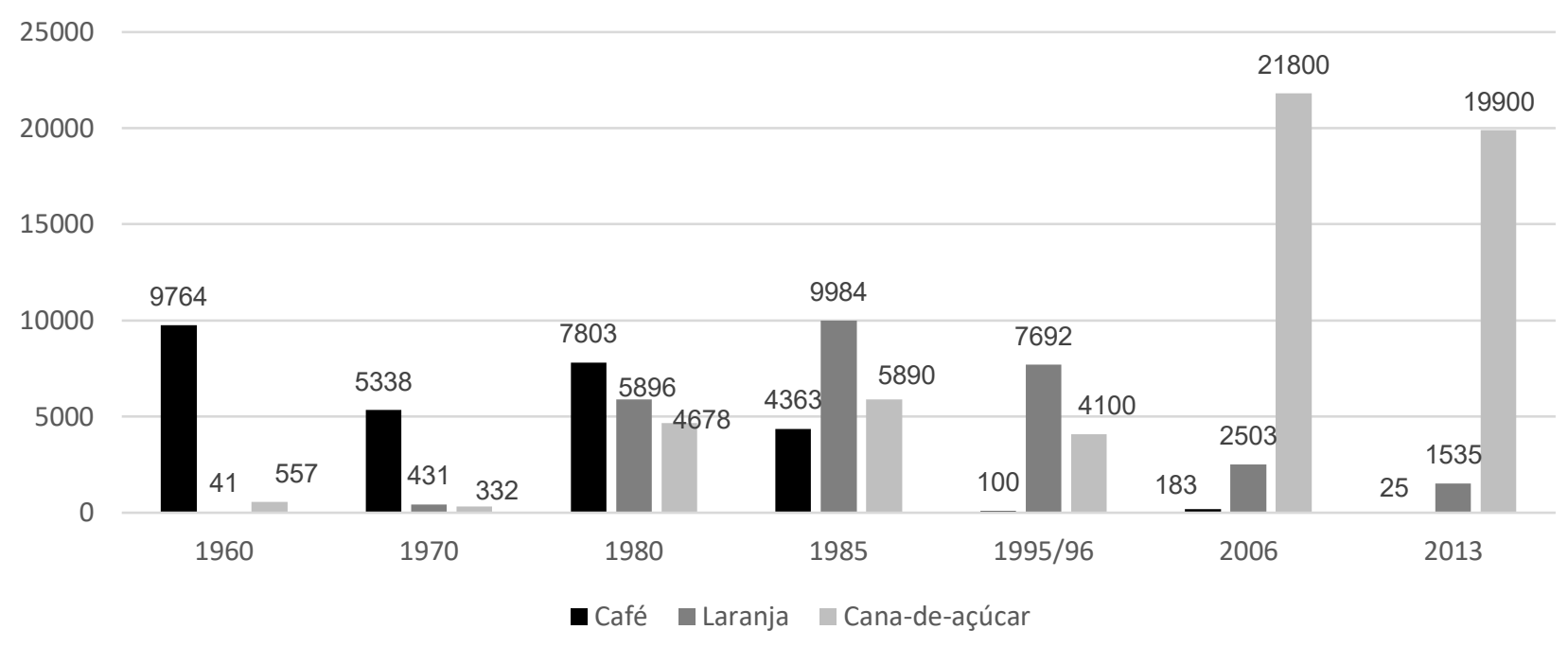

Figura 2 - Área plantada (em hectares) de café, laranja e cana-de-açúcar no município de Tabapuã nos anos de 1960, 1970, 1980, 1985, 1995/96, 2006 e 2013.

Fonte: Censo Agropecuário do IBGE de 1960, 1970, 1980, 1985, 1995/96 e 2006 e PAM de 2013 Acessado em maio de 2015

Organização: PELISSON, G. V. (2015)

A partir desse cenário, foi constatada uma alternativa dos agricultores familiares: os sujeitos da pesquisa se organizam e se articulam para permanecerem e se manterem no espaço rural. Essa “organização" é reflexo de políticas públicas de desenvolvimento regional e não é uniforme, é decorrente de processos, às vezes longos, de transformação da paisagem. No caso da expansão da monocultura de café, a meação, ou melhor, os meeiros.

Os meeiros eram indivíduos que viviam nos interstícios das fazendas de café e plantavam café, porém, o lucro ou mesmo o produto bruto era dividido entre os membros, geralmente um desses era proprietário da terra e os demais tinham participação para plantar o fruto. E assim plantavam, colhiam e repartiam como combinado entre os mesmos. Desse tipo de organização, surgiram em algumas propriedades, as colônias, casas geminadas que serviam de abrigo para esse povo e eram construídas em forma de mutirão.

Em seguida, com a laranja houve auxílio de trabalhadores volantes (boias-frias), alternativa encontrada para adequarem os contratos com as agroindústrias cítricas (que se instalaram na região), os mesmos eram contratados apenas em períodos de colheita. Porém, junto com as agroindústrias do suco de laranja surgiram também, na mesma região, usinas sucroalcooleiras impulsionadas por políticas públicas como o PROALCOOL, principalmente nas três últimas décadas do século XX, impactando e criando novas territorialidades do agronegócio.

Já o dinamismo da cultura canavieira, sem dúvida, remete a um processo de transformações agrícolas, provocadas, principalmente, pelo aumento na demanda por cana. $\mathrm{O}$ 
aumento da cana deve-se ao pioneirismo na década de 1950, que abriu caminhos para a implantação de unidades de usinas e formou um complexo agroindustrial na região.

$\mathrm{E}$, dentre os fatores que proporcionam o aumento do número de agricultores que arrendam suas terras, está a falta de mão-de-obra no campo, a mecanização e a comodidade em ter uma "renda" fixa por um determinado prazo sem ter que se preocupar com o processo de desenvolvimento da produção, pois a responsabilidade do estabelecimento arrendado é totalmente da usina.

Essa influência ou controle que a usina tem sobre o agricultor é uma estratégia da territorialidade que afeta um indivíduo ou um grupo. Ao refletir sobre os motivos que conduziram os produtores familiares a arrendarem suas terras para a produção canavieira, sobre o avanço do capital monopolista no campo brasileiro e a pluriatividade como alternativa de permanência do produtor familiar no campo, observa-se que o processo de territorialização do monopólio, a parir da ótica de Thomaz Jr (1988), é evidenciado pela apropriação crescente da renda fundiária dos grupos usineiros, os quais têm o controle do processo produtivo e consequentemente da determinação do preço da cana-de-açúcar.

O autor deixa explícito que "este processo se desenvolve não uniformemente, mas sim de forma diferenciada, porque não necessariamente os grupos usineiros compram terras. Utilizam em alguns casos a prática do arrendamento. [...] Assim, passa-se a ter uma nova configuração do território" (THOMAZ JR., 1988, p. 99), expressada pelas territorialidades, revelando relações de poder que determinam as configurações territoriais. Elas contribuem para a identificação de quem domina e de quem é dominado nos territórios. As territorialidades também estão expressas nas paisagens de modo que seus componentes revelam as relações sociais, políticas e econômicas.

Porém, essa dominação pode esconder a realidade expressiva da agricultura familiar, uma vez que a expressão "mar de cana" utilizada, por exemplo, por Silva (2005) e Gonçalves (2005), tem a intenção de demonstrar a expansão desse cultivo e suas consequências, sejam elas relacionadas ao tipo de mão-de-obra que as usinas utilizam ou à questão ambiental, como coloca o último autor citado, que chama a questão de "deserto verde", que é também uma forma de afirmar a supremacia das agroindústrias sucroalcooleiras. Mas não se pode generalizar, pois, por exemplo, no município em estudo apesar da cana-de-açúcar ser o maior cultivo plantado e colhido a agricultura familiar tem uma contribuição muito importante e significativa na produção de alimentos e derivados.

O pequeno proprietário rural (compreende o que também tem até 64 ha, renda e produção por meio da unidade familiar) se encontra pressionado pelo grande capital e acaba arrendando suas terras para as usinas, e em alguns casos se desloca para a cidade. Os que persistem utilizam seus poucos hectares dos seus estabelecimentos, ou o que resta próximo a suas residências, para 
cultivarem hortaliças ou lavouras de frutas para o consumo próprio ou para atenderem ao mercado local (como restaurantes e mercados).

Segundo Mussoi (2006, p. 101), a agricultura familiar, pelas suas características "como produtora de alimentos básicos baratos, como reserva de mão-de-obra, como consumidora de insumos industriais, e como geradora de um movimento econômico considerável é, ao mesmo tempo, importante para o modelo geral, e gradativamente excluída dele”.

Por isso, em cenário mais recente, os agricultores que persistem em ficar no campo diversificam a área cultivada, não destinada à cultura da cana, ou melhor, o estabelecimento que não está arrendado com outros cultivos, mantém a diversidade da produção de cultivos.

Uma explicação plausível que torna difícil a permanência do agricultor familiar no campo, e um dos fatores atribuídos é o fato de que as famílias já não são tão numerosas quanto no século XX e anteriores, diminuindo assim a mão-de-obra, além do fato de que as famílias buscam na cidade melhores condições de vida, seja consumo, sejam oportunidades de trabalho ou estudo. No município de Tabapuã, onde é baixa a quantidade de habitantes na área rural, fica evidente o envelhecimento da população que permanece no campo, uma vez que a população rural de 1940 a 2010, segundo a Fundação Seade e o Instituto Brasileiro de Geografia e Estatística - IBGE, reduziu em $95,38 \%$.

\section{PRINCIPAIS CONSTATAÇÕES}

A agricultura familiar no município de Tabapuã sempre esteve presente, desde o colonato paulista, porém, pode-se constatar que sempre houve também uma articulação com uma agricultura industrial por meio da exploração de monoculturas. O café foi um grão muito bem aceito na região desse estudo devido ao solo e aos fatores climáticos. A mão-de-obra para este cultivo não foi escravocrata como em outras partes do estado, grande parte foi de imigrantes europeus.

Com o baixo preço do café, deu-se abertura a novos cultivos como o algodão, o arroz, o feijão e a laranja. Essa fruta (a laranja), que tinha como principal país vendedor os Estados Unidos, devido a uma forte geada, proporcionou ao Brasil abertura para explorá-la, tanto foi que o setor de agroindústria de suco de laranja cresceu bastante, tornando o estado de São Paulo o maior produtor nas últimas décadas do século $\mathrm{XX}$, fato que fez com que os agricultores sem perspectivas com o café aderissem a esta cultura.

A indústria contribuiu de forma direta, uma vez que nas primeiras décadas da metade do século XX eram feitos contratos que facilitavam a vida dos produtores rurais, pois eles não tinham de se preocupar com a colheita da fruta, afinal, mesmo que isso fosse descontado do rendimento do valor final, via-se vantagens. Com as mudanças nos contratos na última década desse mesmo 
século, o agricultor viu-se prejudicado, pois tinha que reinvestir na sua lavoura com o dinheiro que havia ganhado na safra anterior, com o veneno e mão-de-obra volante (boia-fria) para a colheita.

Nesse modo capitalista das empresas lucrarem em cima dos agricultores, muitos deles quase faliram e/ou perderam terras, principalmente os agricultores familiares pouco capitalizados em propriedades pequenas. Muitas histórias foram citadas durante o período de entrevistas relacionadas a conhecidos dos agricultores ou mesmo os próprios, que acabaram se endividando com bancos e perdendo terras.

Porém, a dominação do agronegócio não para por aqui, pois muitos, querendo sair desse modo de vida e terem uma renda garantida, cedem suas terras agora para as usinas sucroalcooleiras devido à comodidade e ao fato de terem uma renda garantida todo o mês, ou até mesmo por endividamento com outra lavoura.

A mecanização, a especialização da mão-de-obra e a expansão da monocultura proporcionam o desiquilíbrio entre os agricultores familiares, que, no caso dos desse estudo, são desarticulados e não são assistidos por uma assistência técnica, provocando em alguns casos a saída do campo.

Pode-se constatar que outro fato que implica na permanência desses indivíduos refere-se aos estudos dos filhos, pois, com a implantação do ensino apostilado do Ensino Positivo, que consiste na mesma dinâmica das escolas privadas, com apostilas, houve fechamento das escolas rurais devido às mesmas terem números reduzidos de alunos e proporcionarem gastos. Consequentemente, esse fato pode ser considerado, sim, como um fator que implica no aumento do êxodo rural no município.

Ao fechá-las, o governo local preferiu recolher esses alunos diariamente em suas residências por meio de um transporte público e levá-los para estudarem na cidade. Com isso, muitos pais preferem mudar para a cidade para que seus filhos não tenham que madrugar para pegarem o transporte e retornarem tarde para suas residências.

Outro fator é a saúde, esses estabelecimentos, principalmente os mais distantes da área urbana, não recebem visitas dos agentes da saúde; um fato que ficou em evidência foi o fechamento também de postos de saúde, como por exemplo, o do bairro rural da serrinha.

O município de Tabapuã possui três bairros rurais. Esses bairros rurais, apesar de não terem sido trabalhados de uma forma mais aprofundada neste trabalho, são de extrema importância ao espaço rural do município de Tabapuã, pois são pontos de encontro, de lazer e de religiosidade (capelas e festas típicas como quermesse) tanto das famílias rurais quanto das urbanas que visitam. 


\section{CONSIDERAÇÕES FINAIS}

A agricultura familiar não está acabando no município, isso pode ser constatado pelos levantamentos dos projetos LUPA, SIDRA e PAM e pelos trabalhos de campo, em que se pode constatar que há produção de alimentos, que a unidade familiar permanece se organizando e encontrando meios/técnicas para se manter no espaço rural. A pluriatividade é uma delas.

A burocracia e a falta de instrução fazem com que muitos agricultores não tenham mercado de venda e é nesse aspecto que este membro familiar é dominado pelas tentações da agricultura patronal.

Constatou-se que nenhum dos entrevistados vende seus alimentos para a prefeitura do município para servirem como merenda escolar e que nem toda a merenda é comprada dos agricultores familiares do município (por não haver demanda, isso pelo fato de que, devido à burocracia, muitos não procuram saber como funciona ou não terminam o processo).

Observou-se, também, a utilização de financiamentos de produção (como os Pronaf), apesar de argumentarem que deve haver melhorias nas políticas de créditos e de garantia de venda. Têm-se então que na maior parte das propriedades visitadas o grupo familiar arrenda para usinas sucroalcooleiras um estabelecimento e em outro tem a maior parte com um cultivo predominante (laranja, limão ou seringueira) e o restante diversifica com outras frutas e/ou horta. Essa é a atual estratégia de manutenção e permanência que os agricultores familiares do município de Tabapuã utilizam como alternativa.

Por fim, considera-se que para entender à produção familiar e às estratégias da agricultura familiar para se manter no campo é preciso estudar/compreender a agricultura patronal, a agricultura empresarial e até o complexo do agronegócio, pois este “sombreamento" permitirá compreender as estratégias de permanência do agricultor nos espaços rurais.

\section{AGRADECIMENTOS}

O presente trabalho foi realizado com apoio da Coordenação de Aperfeiçoamento de Pessoal de Nível Superior Brasil (CAPES) - Código de Financiamento 001.

\section{REFERÊNCIAS}

ABRAMOVAY, R. Paradigmas do capitalismo agrário em questão. 1. ed. Campinas: Hucitec, 1992. 296p.

BERNARDELli, M. L. F. H. Pequenas cidades na região de Catanduva - SP: papéis urbanos, reprodução social e produção de moradias. 2004. 347 f. Tese (Doutorado em Geografia) Faculdade de Ciências e Tecnologia, Universidade Estadual Paulista, Presidente Prudente, 2004. 
BRASIL. Lei Federal $\mathbf{n}^{\mathbf{0}}$. 11.326/2006. Estabelece as diretrizes para a formulação da Política Nacional da Agricultura Familiar e Empreendimentos Familiares Rurais. Disponível em: < http://www.in.gov.br/materiais/xml/do/secao1/2237771.xml>. Acesso em: 09 jun. 2014.

CANASAT. Disponível em: http://www.dsr.inpe.br/laf/canasat/cultivo.html. Acesso em: 19 jan. 2016.

CANDIOTTO, L. Z. P. A agricultura familiar no contexto do rural contemporâneo. In: SAQUET, M. A.; SUZUKI, J. C.; MARAFON, G. J. (Org.). Territorialidade e diversidade nos campos e nas cidades latino-americanas e francesas. São Paulo: Outras Expressões, 2011. p. 275-298.

CRESWELl, J. W. Projeto de pesquisa: métodos qualitativo, quantitativo e misto. 3. ed. Tradução: Magda Lopes. Porto Alegre: ARTMED, 2010. 296p.

GIL, A. C. Como elaborar projetos de pesquisa. 4. ed. São Paulo: Atlas, 2008. 175p.

GONÇALVES, D. B. Mar de Cana, deserto verde? Dilemas do desenvolvimento sustentável na produção canavieira paulista. 1. ed. São Paulo: UFSCAR, 2005. 256p.

GUANZIROLI, C.; ROMEIRO, A.; BUAINAIN, A. M.; DI SABBATO, A.; BITTENCOURT, G. Agricultura Familiar e Reforma Agrária no Século XXI. 1. ed. Rio de Janeiro: Garamond, 2001. $284 p$.

LAMARCHE, H. (Coord.) A agricultura familiar: comparação internacional. 1. ed. Campinas: Editora da UNICAMP, 1993.

Levantamento Censitário das Unidades de Produção Agropecuária do estado de São Paulo- LUPA. Área Cultivada, Município de Tabapuã, Estado de São Paulo, 2007/08 (em hectares). Disponível em: www.cati.sp.gov/projetolupa/dadosmunicipais/pdf/t580.pdf. Acesso em: 24. jan. 2020.

LINDNER, M. A organização do espaço sobre o olhar das ruralidades: estudo da paisagem e lugar no município de São João do Polênise, Rio Grande do Sul. Rio Claro: UNESP, 2001. 208 f. Tese (Doutorado em Geografia) - Instituto de Geociências e Ciências Exatas, Universidade Estadual Paulista, Rio Claro, 2011.

MUSSOI, E. M. Agricultura familiar, extensão rural e a nova política nacional de Assistência Técnica e Extensão Rural. In: LIMA, J. R. T.; FIGUEIREDO, M. A. B. (Org.). Extensão rural, desafios de novos tempos: agroecologia e Sustentabilidade. Recife: Bagaço, 2006.

NEVES, D. P. Formas tutiladas de condição camponesa: colonato e morada na agroindústria exportadora. In.: NEVES, D. P.; SILVA, M. A. M. (Orgs.) Processos de constituição e reprodução do campesinato no Brasil: formas tutiladas de condição camponesa. São Paulo: EDUNESP, 2008. p. 137-161.

RICHARDSON, R. J. Pesquisa Social: métodos e técnicas. 3. ed. São Paulo: Atlas, 2008. 334p.

SAQUET, M. A. Abordagens e concepções de território. 1. ed. São Paulo: Expressão Popular, 2007. 192p. 
SCHNEIDER, S. (Org.). A diversidade da Agricultura Familiar. 2. ed. Porto Alegre: Editora da UFRGS, 2009. 300p.

SILVA, M. A. M. Trabalho e trabalhadores na região do "Mar de Cana e do Rio de Álcool". AGRÁRIA, n. 2, p. 2-39, 2005.

SUERTEGARAY, D. M. A. Pesquisa de campo em Geografia. 2009. Disponível em:< http://www.uff.br/geographia/ojs/index.php/geographia/article/view/78/76>. Acesso em: 26 jan. 2015.

THOMAZ JR, A. A territorialização do monopólio: o caso das agroindústrias em Jaboticabal. 1988. Dissertação (Mestrado em Geografia Humana) - Universidade de São Paulo, São Paulo, 1988.

VEIGA, J. E. O desenvolvimento agrícola: uma visão histórica. 1. ed. São Paulo/SP: Hucitec, 1991. 240p. 